\title{
EL ESPACIO PÚBLICO COMO EXPERIENCIA SOCIAL
}

THE PUBLIC SPACE AS A SOCIAL EXPERIENCE

O ESPAÇO PÚBLICO COMO EXPERIÊNCIA SOCIAL
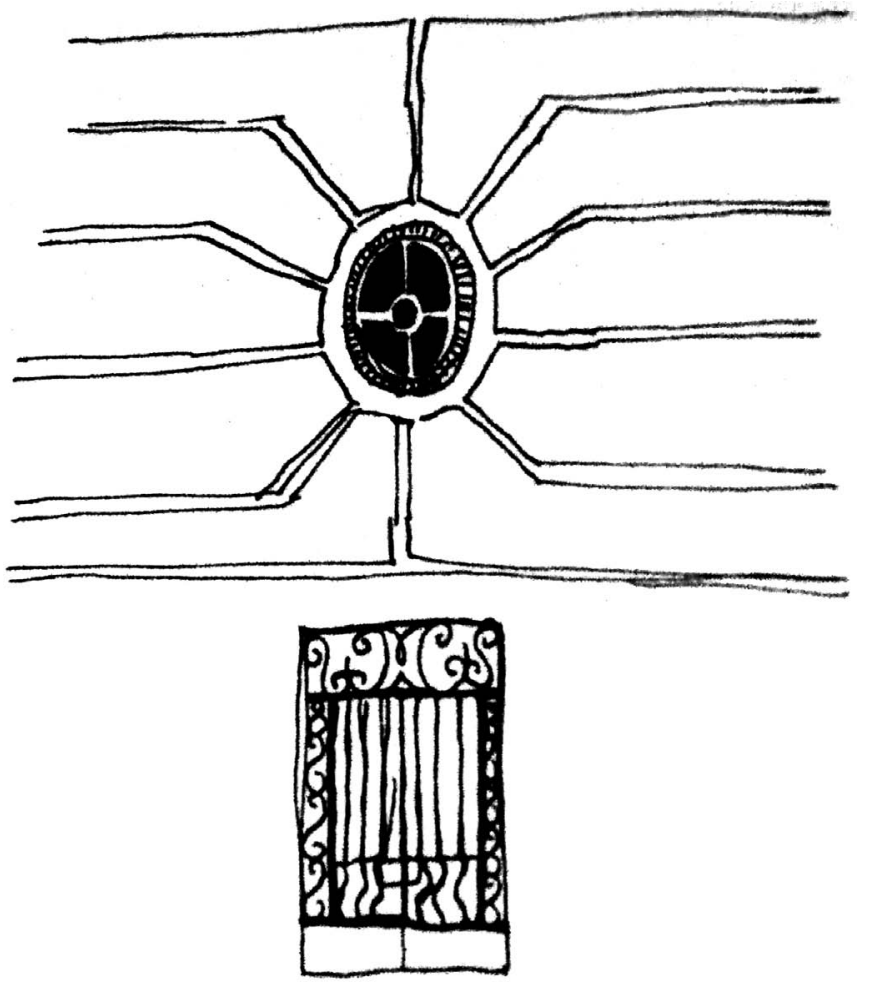

Por:

Catalina Ballesteros Garzón

Comunicadora Social

Universidad del Valle

catalina.ballesterosg@gmail.com

Melissa Martínez Zuleta

Comunicadora Social

Universidad del Valle

mmzuleta00@gmail.com

Lina Marcela Sánchez Calderón

Comunicadora Social

Universidad del Valle

lina.ms.calderon@gmail.com

Resumen: El presente artículo de reflexión indaga sobre el espacio público como experiencia social a partir de la reflexión sobre conceptos como modernización y urbanismo, y su relación con los actores que influyen en dicho espacio. En primer lugar, se estudia el espacio público como un lugar de tensiones, reasignaciones de sentido, y fronteras entre lo público, lo íntimo y lo privado. Los transeúntes se desenvuelven siguiendo ciertos esquemas 'teatralizados'. Pero, a diferencia del teatro, en el espacio público no hay una puesta en escena y las representaciones de la vida cotidiana son improvisaciones. Además, se reflexiona sobre cómo los procesos de renovación urbana moldean a los actores sociales del espacio público, entendiendo que los diseños del urbanismo se transforman según las escrituras de los andantes en la calle. De este modo, las sociabilidades que ocurren no deberían entenderse al margen de los proyectos que abren paso a la renovación de las ciudades. 
Palabras Clave: Transformación urbana, cultura urbana, espacio público, transeúnte, sociabilidad.

\begin{abstract}
This reflective article inquiries about the public space as a social experience by reflecting on concepts such as modernization and urbanism, and their relationship with the social agents that affect that space. First of all, it studies the public space as a place of tensions, changes of meaning, and borders between the publicness, the intimacy and the privateness. The pedestrians behave following some "histrionic" patterns. Nevertheless, differently from the theatre, there is not a Mise-en-scène in the public space, and everyday life is an improvisation. In addition, it is reflected on how processes of urban renovation shape the social agents of the public space, taking into account that urban design are transformed according to the passersby's will. Thus, the social relationships that take place in the public space should not be understood excluding the projects that allow the renovation of the cities.
\end{abstract}

Keywords: Urban transformation, urban culture, public space, pedestrian, sociability.

Resumo: Este artigo de reflexão indaga sobre o espaço público como experiência social a partir da reflexão sobre os conceitos como modernização e urbanismo, e a sua relação com os atores que influem nesse espaço. Em primeiro lugar, estuda-se o espaço público como um lugar de tensões, mudanças de sentido, e fronteiras entre o público, o íntimo e o privado. Os passantes desenvolvem-se seguindo alguns padrões 'teatralizados'. Porém, a diferença do teatro, no espaço público não há uma posta em cena e as representações da vida cotidiana são improvisações. Além, reflexiona-se sobre como os processos de renovação urbana amoldam aos atores sociais do espaço público, entendendo que os planejamentos do urbanismo mudam-se de acordo com as escrituras dos passantes da rua. Deste jeito, as relações sociais que ocorrem não devemse entender por fora dos projetos que abrem as portas das renovações das cidades

Palavras-chave: Transformação urbana, cultura urbana, espaço público, passante, sociabilidade.

El siguiente artículo hace parte del trabajo de grado Asfalto no es Progreso. Usos sociales del espacio público en períodos de transformación urbana, realizado en un periodo de aproximadamente tres años -entre el 2011 y el 2014- para obtener nuestros títulos de pregrado de Comunicadoras Sociales en la Universidad del Valle, en Cali, Colombia. El trabajo consistió en el desarrollo de una estrategia de sistematización cuya pretensión fue dilucidar experiencias del urbanismo, vividas por una familia en particular que habita hace más de 30 años en el centro de la ciudad de Cali, zona aún propensa a dejar de existir como la conocemos, debido a los proyectos de renovación urbana. 
De la misma manera que otras ciudades del país, Cali (Colombia) creció desde su centro. A principios del siglo XX, la élite de la ciudad creó fábricas y negocios motivada por el auge del ferrocarril, llegaron inmigrantes en busca de nuevas oportunidades laborales, con quienes surgieron hoteles y lugares de paso de baja categoría. El ritmo urbano del centro se fue transformando, pasó de ser el nido de gran parte de la actividad comercial y económica de la ciudad, a ser el nicho de los trabajos informales, ventas minoristas y ambulantes, y, en las áreas más deprimidas, consumo y expendio de sustancias psicoactivas, e inquilinatos. El crecimiento de la ciudad ha traído varios intentos de modernización desde los que se planean transformaciones que le cambien la cara al espacio público del centro de Cali. Iniciativas "modernizadoras" como las del Proyecto de Renovación Urbana Ciudad Paraíso pretenden demoler las viejas y abandonadas fachadas por construcciones de asfalto que mejoren la apariencia del sector y lo saquen del atraso.

Para el desarrollo metodológico del trabajo, realizamos descripciones detalladas a partir de las narraciones que los integrantes de la familia hicieron sobre su casa y su barrio, lo que nos permitió entender la experiencia concreta de la vida dentro de una cultura particular. Utilizamos ejercicios de cartografía social en varios momentos durante el trabajo de campo, cuyo resultado fueron 3 mapas (el mapa del presente, el mapa de los cambios que se darían en el sector según Ciudad Paraíso y el mapa de los deseos) en los cuales logramos, además de que ellos interactuaran con ellos, diálogos que dieron cuenta de muchas de sus relaciones con los lugares que habitan y transitan en sus cotidianidades.

Tanto este artículo como el resto de nuestro trabajo de grado, surgen de la necesidad por indagar cómo las transformaciones urbanas influyen en la cotidianidad de quienes habitan los espacios: ¿cuál es la ciudad pensada desde los proyectos de remodelación urbana? y ¿cuál es la ciudad que practican sus habitantes? A partir de esta investigación sentimos la importancia de continuar reflexionando acerca del espacio público como una experiencia social. Antes de realizar la inmersión en nuestro trabajo de grado nos pareció necesario entender cómo funciona la calle y el espacio público; con esta intención, ahondamos en conceptos que nos resultaron claves previos a dicha inmersión: urbanismo, espacio público, espacio privado, cultura urbana, transformación urbana, entre otros. Conceptos que giran en torno a la idea de ciudad y que abordamos en el texto que sigue a esta introducción, resultaron definitivos para entender las formas de habitar los lugares. Entendimos, además, que el espacio público no debe concebirse simplemente como un lugar meramente "público" sino como un espacio de intercambio entre los individuos donde hay tensiones y relaciones más complejas de lo que realmente aparentan. 


\section{Urbanismo: entre la cultura urbana y la urbanística}

La modernización de las ciudades, fenómeno que varía según las particularidades de cada sociedad, transforma la relación de los habitantes con la calle. El urbanismo, por ejemplo, como consecuencia de la modernización, impulsa maneras en que los sujetos deben comportarse en lugares públicos como plazas, parques y avenidas. A partir del urbanismo promovido entre los años 30 y $50^{1}$ las vías de tránsito se transformaron en extensos andenes, los cuales facilitaron las aglutinaciones de miles de transeúntes que vivieron la calle como un lugar predominantemente funcional (Ariès, 1995).

Con el urbanismo se ordena la ciudad y así surge la idea de espacio público. Desde entonces, las ciudades tienden a ser divididas en lugares comerciales, residenciales y de ocio, conectados entre sí por vías cada vez más rápidas. Este fenómeno obedece a una nueva "lógica de circulación y seguridad" (Ariès, 1995:283) en la que impera el orden. A partir del urbanismo, la calle dejó de ser un lugar destinado a la permanencia, y los niños, quienes la usaban como lugar de esparcimiento, fueron alejados de ella.

Así, la calle, deja de ser un lugar en donde se construyen formas de sociabilidad, para convertirse en un 'lugar de paso':

Se trataba de limpiar la calle de esa plebe indómita que por mucho tiempo se había aceptado, no siempre de buen agrado, pero sin intención de prescindir de ella y que poco a poco se fue volviendo sospechosa, inquietante y condenada. (...) La calle es inmoral en la medida en que se permanezca en ella. Sólo escapa a la inmoralidad cuando se convierte en lugar de paso y cuando pierde, como sucedió con el urbanismo de los años 30 a 50, el carácter y la tentación de la permanencia (Ariès, 1995, p. 283).

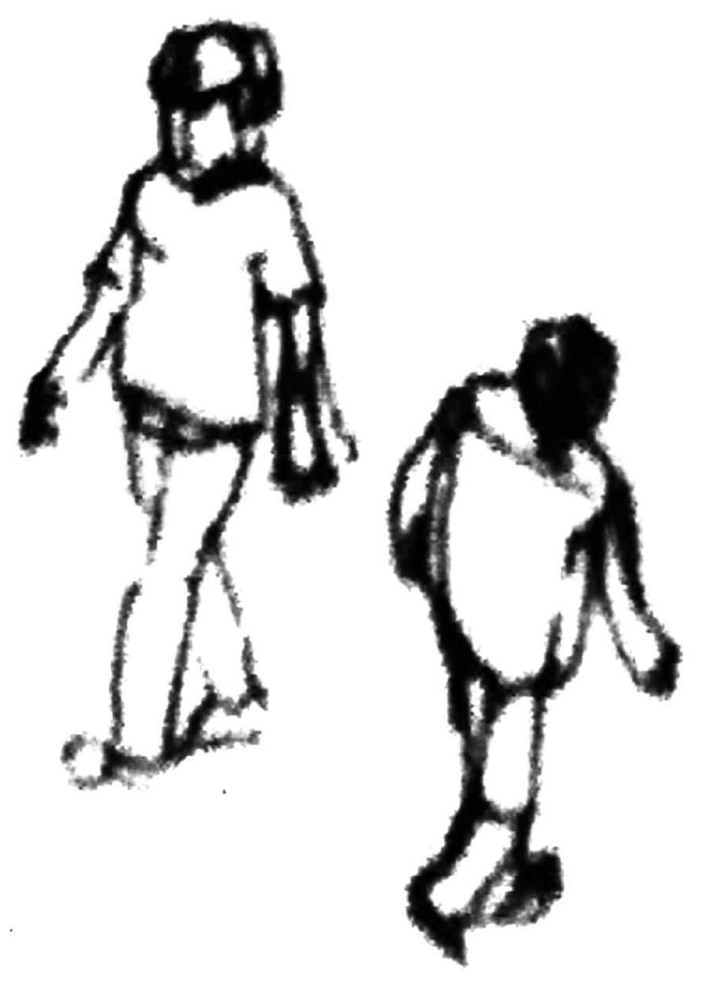


Con el vuelco de la estructura física de las ciudades, el urbanismo provoca relaciones que están llenas de tensiones. Una de ellas, según Manuel Delgado (2007, p.11), es la tensión que se establece entre "el conjunto de maneras de vivir en espacios urbanizados y la estructuración de las territorialidades urbanas": un tira-y-afloje entre la cultura urbana y la cultura urbanística; entre lo urbano y la estructura física de la ciudad. La cultura urbana la entendemos, como "una trama de trenzamientos sociales esporádicos, aunque a veces intensos" (Delgado 1999, p. 28), que toma forma, de manera 'poco cohesionada', en el espacio público y que, por tanto, da lugar a una multiplicidad de sentidos atribuibles a la calle. Se contrapone al significado de cultura urbanística, ya que éste apela al orden como único sentido asignable a la calle.

Lo que sucede en las calles y las prácticas que se dan en ellas conforman lo urbano, lo que a su vez suscita "un tipo de espacio social: el espacio urbano" (Delgado, 2007, p. 11). Sus protagonistas son miembros de estadía no permanente; sin inscripción previa. Se trata de una colectividad de formación efervescente que se va tejiendo en medio de todo tipo de formas relacionales. En el espacio urbano no importa la identidad ni las afiliaciones; “importan las señales de adecuación al comportamiento propio y ajeno” (2007, p.11); las señales de calma o peligro que se dan en la exterioridad. En la calle se desarrollan hechos, sucesos, sociabilidades entre personas que no tienen ninguna conexión entre sí; no las une nada en particular, sólo el hecho de transitar. Como consecuencia, los transeúntes evalúan el entorno a partir de las apariencias de los otros.

El espacio urbano es un lugar que no tiene límites espaciales fijos; es volátil y sus fronteras varían constantemente. No tiene un lugar asignado, en tanto son los transeúntes quienes lo caracterizan, a pesar de las intenciones de la urbanística. La calle, por tanto, es reelaborada por las prácticas y discursos de sus usuarios. Los diseñadores de las ciudades, los urbanistas, buscan moldear la cultura urbana, dando a los ciudadanos un parque, una plaza, una calle que deben usar evitando el conflicto. En estas pretensiones de la mejoría material, la municipalidad diseña ciudades funcionales y sus diseñadores buscan eficiencia en los espacios que construyen, a partir de una legibilidad de la estructura. En síntesis, buscan apaciguar la inestabilidad de lo urbano.

Delgado (2007) hace una analogía entre las prácticas que se dan en las calles y los accidentes naturales, pues en las calles se presentan "obstáculos de navegación” (Delgado, 2007, p. 17) que alteran el camino previamente determinado. La conformación de sociedades modernas con pretensiones urbanísticas no logra trazar normas de comportamiento fijas. Aun cuando la municipalidad, por ejemplo, define límites entre las zonas residenciales -destinadas para vivir lo íntimo y lo privado- y los lugares de paso -con características expresamente funcionales-, los transeúntes los quiebran y convierten su andar en un 'obstáculo de navegación'. Las relaciones que establecen los transeúntes con su calle hacen que, como plantea Isaac Joseph (2002, p.15), "el espacio público esté irremediablemente truncado" por dispersiones, discontinuidades, digresiones y formas de adaptación. Cualidades como la dispersión permitirían que la cultura urbana dispare en múltiples direcciones, afectando el ordenamiento urbanístico de las ciudades. 
Delgado (2007) argumenta que en "los espacios urbanos parece que no se previera la sociabilidad”, (Delgado, 2007, p. 15) como si la planeación municipal no calculara las relaciones que se podrían dar en la calle, o no tuviera en cuenta la innumerabilidad de habitantes que hacen uso de ella. Una vez reformadas las calles, las edificaciones, rígidas y geométricas, se llenan inevitablemente de corrientes humanas que vuelven difuso el paisaje, a partir de tantas escrituras como transeúntes anden la calle. Si las calles se quedaran vacías de vida humana, podríamos leer con mayor facilidad su morfología: las calles se podrían entender; serían comprensibles en tanto tienen una coherencia que las distribuye. Pero al espacio urbano, ese que aparece y desaparece, no se le puede adscribir una lógica fija, ni se le puede pedir que responda a un único código. No hay en lo urbano "nada parecido a una verdad por descubrir" (2007, p. 17).

La estabilidad y el orden como atributos impuestos a lo urbano, tienden a asegurarse gracias al papel desempeñado, de un lado, por entes estatales de control como la policía y, de otro, por políticas como el civismo, paradigma de la vida en consenso, de la convivencia amable y de la buena conducta. Lo anterior, es permitido gracias a una clase social en particular, capaz de replicar las normas que propone el urbanismo: nada más ideal que "una clase media universal que se dedique a las virtudes de la buena urbanidad” (Delgado, 2007, p. 18). Ese afán por ordenar la ciudad está ligado al desarrollo del capitalismo que estimula la propiedad individual del espacio en desmedro de su apropiación colectiva, "excluyendo (de las calles) al indeseable o al ingobernable” (Delgado, 2007, p. 18).

\section{Apropiaciones y resignificaciones en el espacio}

Patricia Fortuny (2010) plantea, hablando sobre la experiencia de migrantes mexicanos en Estados Unidos, que una de las maneras de apropiarse de lugares nuevos es resignificándolos con símbolos que los conecten con los lugares de origen. Los migrantes, en este caso, al buscar un modo de vida diferente en ciudades extranjeras, respondieron utilizando en aquellas calles, símbolos e imágenes religiosas que los conectaban a sus lugares natales. Para ella, la confluencia de variadas culturas en el espacio público "modifica el acomodo espacial y social” (Fortuny, 2010, p. 22). De esta manera, las relaciones entre practicantes y espacio público pasan por un percibir, utilizar y habitar los espacios, a partir de hibridaciones por las cuales el sistema estructurado no es un lugar fijo y cristalizado, sino un lugar movedizo. El orden preestablecido, por tanto, está en potencia de ser modificado, dependiendo de los variados modos de sociabilidad y de las distintas relaciones que tejen los transeúntes con su espacio. Los nuevos caminos que trazan se equiparan a lo que María Gracia Castillo (2010) reconoce como "apropiación ciudadana" (Gracia Castillo, 2010, p. 136) . Dicha apropiación, pasa por un "proceso de identificación construido consuetudinaria, lenta y colectivamente". 
Los espacios público, privado e íntimo podrían tener límites difusos que no se deriven enteramente de locaciones físicas, sino que también se establezcan en el terreno de lo simbólico. Así, los límites simbólicos del espacio público tendrían perforaciones por donde se filtrarían acciones de los otros espacios. La correspondencia entre las locaciones físicas y los límites simbólicos, contribuiría a la "formación de procesos de identificación, uso y apropiación” (Castillo, 2010, p.140), que vincularían a las primeras y los segundos con la comunidad. No obstante, Castillo (2010, p.138) reconoce, al igual que Ariès, que la "dinámica del urbanismo capitalista del siglo XX” altera los límites simbólicos a partir de la domesticación de la calle -lo que para Ariès es el movimiento de privatización- y la imposición de reglas cívicas:

La institución de lo cívico nacional en detrimento de lo local no es algo estático, sino un proceso que ha atravesado diferentes etapas que tienen que ver con la dinámica que el capitalismo ha impuesto a los diferentes aspectos de la vida social, entre ellos a las urbes, a su espacio y por tanto al uso que de él hacen sus habitantes (Castillo, 2010, p.140).

Tal domesticación la concebimos como una reducción de sentidos atribuibles a la calle. De esta manera, se restringen los usos ligados al espacio público, afectando la sociabilidad entre sus practicantes.

Fortuny (2010) ve el espacio público como un lugar en donde la solidaridad cumple una función crucial. La solidaridad se vincula a procesos comunitarios que les permiten a los sujetos sociales generar lazos afectivos con lugares a los que no tendrían derecho, con espacios que les resultarían ajenos o con escenarios en donde el papel que deben desempeñar les resultaría extraño. En este caso, habría un uso social del espacio público mucho más específico. No se trataría de 'corrientes humanas' (Delgado, 2007, p.15), sino de actores que cargan de nuevos sentidos y afectos aquello que se les concede como público. Se trata de un uso social que reconfiguraría el espacio: aquello que es ajeno debe convertirse en algo propio. De esta manera, el espacio público se llena de fronteras simbólicas y acuerdos tácitos propuestos por quienes construyen su cotidianidad allí. Así, el espacio adquiere atributos ideológicos y afectivos.

Si con el urbanismo de los años 30 y 50 se proponía alejar a las clases subalternas ${ }^{2}$ de las calles, podemos pensar que el espacio público es un lugar para cierto tipo de clases sociales. Aunque existan tensiones entre la cultura urbana y la cultura urbanística, esta tensión sólo podría ser generada por los practicantes que se alejan más de las clases subalternas y menos de las dominantes. Sin embargo, pensamos que el estudio sobre el uso social del espacio público debe considerar las apropiaciones que surgen de las clases cuyo uso de la calle fue estigmatizado o, inclusive, negado. Así, aproximaciones como las de Fortuny (2010) nos permiten pensar en un tipo de practicante al que no se le puede categorizar, por ejemplo, solamente como transeúnte, pues el uso que hace de la calle desborda el significado de lo público. Se trata de practicantes que convierten su cotidianidad en un actuar que reasigna sentidos y significados al espacio. 


\section{Actores sociales del espacio público}

María Cristina Ruiz (2009) señala que el actor no debe pensarse como un sujeto individual sino como "la encarnación de una identidad colectiva, producida desde un universo simbólico” (Ruiz, 2009, p. 83). Desde esa perspectiva, los actores sociales del espacio público no serían solamente un conglomerado de transeúntes que practican la calle de diversas maneras, sino sujetos sociales que, al actuar, portan diversos roles que dan cuenta de un escenario. Los actores son, por tanto, "sujetos concretos identificables en una experiencia. Pero son, a su vez, perspectivas particulares desde las que la experiencia se narra" (Ruiz, 2009, p. 82). Así, no bastaría con reconocer las prácticas sociales de los actores. Se necesitaría indagar en los sentidos y las interpretaciones que cada uno de ellos hace de la experiencia.

Los actores sociales del espacio público son sujetos que actúan en un escenario, no desde una identidad cristalizada, sino desde unos roles permeados del universo simbólico constituido por la cultura de lo urbano y las lógicas urbanísticas de la calle. La diversidad de roles permite indagar en las interpretaciones que "hacen los actores de su lugar social y de su acción en la experiencia” (Ruíz, 2009, p. 90). En el espacio público como lugar social, los sujetos portan diversos roles que interpretan un mismo papel: el de actor social en el espacio público.

Según Erving Goffman (1953), "al mismo tiempo que portamos un rol" (Goffman, 1953, p. 92), como el del transeúnte que camina por la acera, "interpretamos un papel” (Goffman, 1953, p. 92): en caso de que un transeúnte tropezara al lado de un tumulto de personas, pasaría a ser un sujeto observado. Allí la interacción obligaría al sujeto a transmitir un mensaje intencional. La relación entre el rol inconsciente y el papel interpretado hace que el transeúnte proyecte una imagen de sí en tanto actor social. De esta manera, en la vida cotidiana, al igual que en el teatro, los actores se desenvuelven de una manera específica y siguiendo ciertos esquemas. Por tanto, hay una teatralidad inherente al espacio público. Sin embargo, a diferencia del teatro, en el espacio público no hay una puesta en escena y las representaciones de la vida cotidiana se vuelven improvisaciones para las cuales sólo se tiene cierta preparación. En el espacio público el actor desconoce lo que ha de hacer y el efecto que puede producir su actuar; sin embargo, se le exige que aprenda suficientes fragmentos del papel para que sea capaz de improvisar, cualquiera que sea el rol que le toque.

El papel del transeúnte va más allá del caminar, pues existe una "escritura y unas elecciones" que se toman al andar la ciudad. A esta analogía, entre el acto de enunciar y escribir con el de caminar, Michael De Certeau (1996) la llama "retórica del andar". De esta manera, existen múltiples escrituras del espacio público y por tanto, los textos urbanos se escriben a partir de cómo los actores se relacionan con la calle; es decir, a partir de las diversas formas en que "afirman, sospechan, arriesgan, transgreden y respetan" ese espacio (De Certeau, 1996, p.112). Tales modos de andar y tropezar con los obstáculos propios de lo urbano, se traducen en decisiones de estilo o en puntos de giro. El peatón se apropia "del sistema topográfico, del mismo modo en que el locutor asume y se apropia de la lengua" (1996, p. 112). 
Si pensamos en la diferencia entre portar un rol e interpretar un papel, y en las múltiples escrituras que podríamos hacer del espacio urbano, podemos afirmar que éste espacio, como escenario de la vida colectiva, fluctúa de manera desequilibrada. Sin embargo, las multitudes urbanas, las cuales solo tienen en común la presencia compartida, funcionan por medio de saberes tácitos, como las decisiones de estilo, que permiten trazar escrituras en función de la estabilidad del espacio urbano. La calle es un espacio de sonámbulos libres de pasiones, donde el transeúnte se desdobla al atravesar la calle, renunciando a encontrar el sentido de su acción: es un sonámbulo que obedece rutinas (Joseph, 2002). Éstas le anticipan una lógica que depuraría la situación de toda ambigüedad.

No debe existir algún tipo de fraternidad en el espacio público, pues los transeúntes conviven con "el terror a la identificación y a la invasión" (Joseph, 2002, p. 17). La fraternidad iría en detrimento del orden social establecido en el espacio público ya que provocaría confrontaciones e interferencias que no permitirían al transeúnte seguir por su camino. El espacio público entonces se convierte en:

El espacio del anuncio, como forma de distancia respecto del papel, en el espacio del look. Espacio sonámbulo, siempre superficial, en el que la cara se convierte en fachada y en el que todo debe ser negociado porque todo es problemático ( Joseph, 2002, p. 79).

A pesar de que al actor social se le podría considerar un sonámbulo, creemos que es necesario entender que el espacio público, al ser "un escenario en el que se desarrolla la vida humana" (Castillo, 2010, p. 135), está en potencia de múltiples formas de adaptación e interpretación, según las cuales no todas las acciones de los actores sociales pasan por la rutina, pues los caminos que escriben otorgan otros sentidos al espacio.

Si bien el urbanismo propone formas de andar la calle, estas formas se revierten cuando aparecen las tensiones entre lo urbano y la urbanística. Las hibridaciones surgidas dentro del proceso de modernización permiten que las vías rápidas y funcionales sean reinterpretadas y contestadas a partir de un accionar que pasa por la resignificación simbólica: los andenes anchos e impecables que agrupan a cientos de transeúntes rápidamente se llenan, también, de vendedores ambulantes y el cemento se cubre de grafitis y murales. Esto se da debido a "la polisemia de los espacios y su vinculación con la situación sociocultural de los sujetos, con el género y la generación con la que se identifican" (Castillo, 2010, p. 148). El actor social, entonces, no solamente se vincula con el espacio público en términos de funcionalidad, sino en términos de apropiación simbólica.

El espacio público es un lugar que se construye a partir de las políticas urbanas funcionalistas que si bien provocan el "sentimiento de anomia de los citadinos" (Castillo, 2010, p. 172), también da lugar al encuentro colectivo como forma de resistencia y como alternativa desde la cual al espacio se le reasigna el sentido de lo público: 
Se ha fomentado la formación de instituciones, agrupaciones, espacios no vinculados al lugar de residencia, en los que los individuos pueden encontrar referentes y que podrían considerarse como espacios semipúblicos. Sin embargo, circunstancias relacionadas con lo económico, lo educativo, el tiempo, la edad y el género, impiden a algunos grupos acceder a dichos espacios, por lo que fortalecen, renuevan y actualizan tradiciones y solidaridades relacionadas con los lugares de residencia, a través de lo cual cuentan con referentes, se sienten integrados y dan sentido a sus vidas (Castillo, 2010, p. 172).

$\mathrm{Al}$ actor social, entonces, no se le debería concebir solamente como un sujeto que obedece los roles asignados por el urbanismo, sino también como un sujeto que resignifica tal movimiento provocando una cultura de lo urbano. Así, al igual que Goffman, pensamos que "los sujetos son actores que improvisan" (Goffman, 1953, p. 96). En este caso, la improvisación reinterpretaría el espacio público. Patricia Fortuny, por ejemplo, indaga en el papel que podría jugar el actor social, una vez el espacio que

le es asignado como público, le resulta extraño. El papel que interpreta pasa por una adaptación creativa, en donde al nuevo espacio se le asignan atributos de su cultura, "logrando apropiarse de esa geografía ajena para transformarla en una más propia" (Fortuny, 2010, p. 34). La improvisación sería una forma de contestar a un espacio que es ajeno.

\section{Usos sociales del espacio público en periodos de transformación urbana}

Sobre la noción de espacio público se ha reflexionado desde distintas perspectivas. Mientras autoras como Rossana Reguillo (1996), María Castillo (2010) o Patricia Fortuny (2010) lo consideran como uno de los lugares donde se potencia la solidaridad entre los actores sociales, Manuel Delgado (2007) e Isaac Joseph (2002) lo ven como un espacio de flujo en el que se obedecen rutinas. A pesar de lo disímiles que resultarían ambas perspectivas, ambas consideran que el espacio público surge para apaciguar la inestabilidad de la sociabilidad que ocurre en las calles.

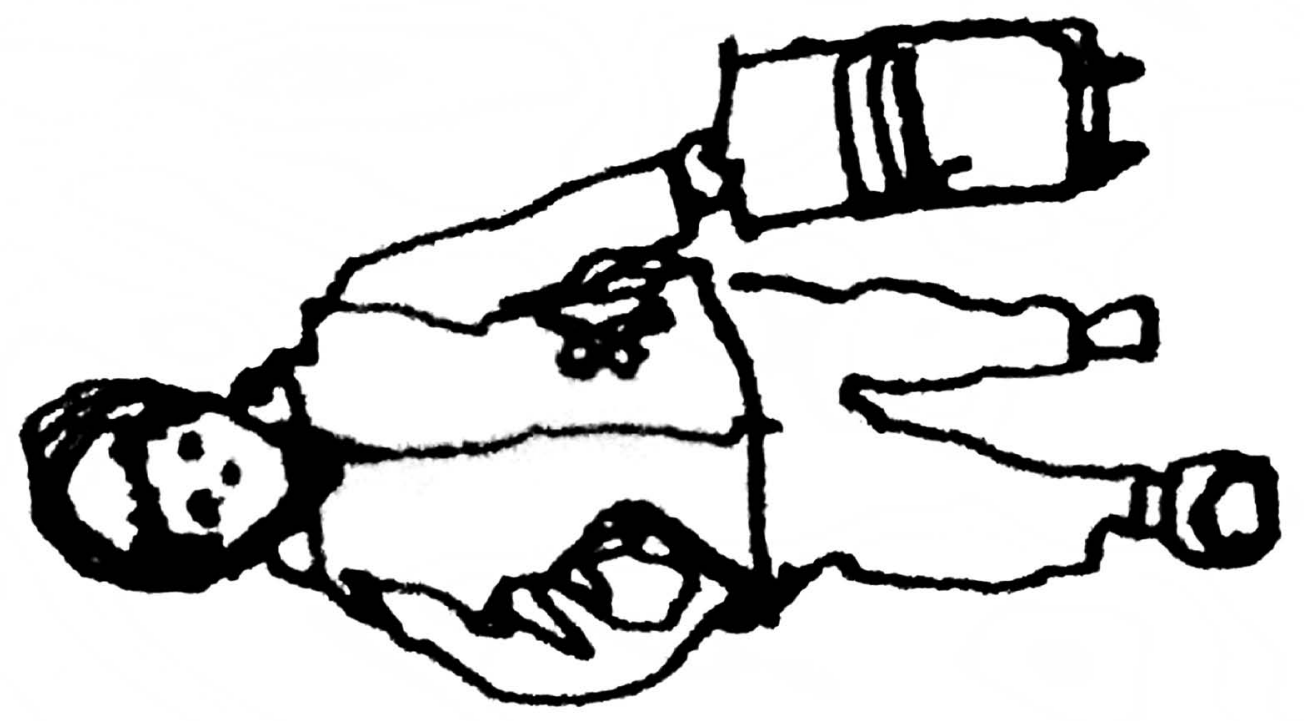


La idea de espacio público nace, en gran medida, para reconfigurar la dimensión social de la calle. La cultura urbanística (Delgado, 2007, p. 11), el movimiento de privatización (Aries, 1995, p. 283), la dinámica del urbanismo capitalista (Castillo, 2010, p. 139) nos advierten sobre las transformaciones por las que atravesó la calle, una vez se convirtió en espacio público. Tales nociones apuntan a la idea de que había que reducir los sentidos atribuibles a la calle para poner orden a las ciudades: una calle no podía ser al mismo tiempo que lugar de juego, vía de tránsito; no podía hacer las veces de plaza de mercado y lugar de vivienda. La idea de lo público tiene fronteras simbólicas que privatizan el uso de las calles, en el sentido de que cada espacio empieza a usarse para un fin determinado. Así el flujo de transeúntes se mantiene equilibrado.

Rosana Reguillo plantea que "la reducción de sentidos asignados a la calle" (Reguillo, 1996, p . 22) conduce al mantenimiento del equilibrio de la misma. Esa reducción es, a su vez, un producto cultural si se entiende por cultura "los sistemas de representación y acción de actores en el espacio urbano y en la lucha asimétrica por la definición política de la realidad" (Reguillo, 1996, p. 19). Tal reducción de sentidos se podría dar cuando los proyectos de ciudad proponen un modelo de ciudadano universal que responde a un conjunto fijo de características (1996: 68). Este modelo entraría en tensión con los sentidos que construye el actor social de su experiencia urbana, del mismo modo en que "la dinámica del urbanismo capitalista del siglo XX", que expone María Gracia Castillo (2010, p. 139), introduce lo cívico-nacional “en detrimento de lo local”.

De la misma manera, Sagástegui ve la calle como un "espacio que se moldea desde la sociabilidad” (Sagástegui, 2010, p. 189). Por tanto, las transformaciones urbanas deberían ser escenarios de vinculación entre la gente y las decisiones que afectan el espacio público. A pesar de ello, "la participación ciudadana está constreñida por múltiples factores y situaciones que atentan contra las posibilidades reales que tienen los habitantes de incidir en las decisiones que marcan el desarrollo de su ciudad" (Sagástegui, 2010, p. 188).

Si comprendemos, entonces, que los caminos prediseñados desde el urbanismo se transforman según las escrituras de los andantes en la calle, las sociabilidades que ocurren en el espacio público no deberían entenderse al margen de los proyectos que abren paso a la renovación de las ciudades. Es el cruce entre lo tradicional, lo heredado y lo innovador en donde la sociabilidad se transforma para convertirse en un nuevo uso social del espacio urbano. Por tanto, habría que pensar si acaso, al igual que con la cultura de las clases subalternas y la cultura de las clases dominantes, podríamos hablar de circularidad entre la cultura urbana y la cultura urbanística; entre los usos sociales que propone el urbanismo y los que proponen aquellos actores a los que tiempo atrás les fue negado el uso del espacio público. 


\section{Referencias}

Ariès, P. (1995). "El niño y la calle, de la ciudad a la anticiudad” y "La Familia y la Ciudad”. En: Ensayos de la memoria 1943-1983. Colombia: Norma, p. 283-310.

Castillo, M. G. (2010). "El espacio público vivido. Tres periodos urbanos del siglo XX vistos a través de un barrio citadino”. En: Ciudad, espacio público y sociabilidad. Guadalajara: Universidad de Guadalajara, p. 135-182.

De Certeau, M. (1996). "Andares de la ciudad”. En: La invención de lo cotidiano I. Artes de hacer. México: Universidad Iberoamericana, p. 103-122.

Delgado, M. (1999). "La sociedad y la nada” En: El animal público. España: Anagrama, p. $85-130$.

. (2007). "De la ciudad concebida a la ciudad practicada" y "Apuntes metodológicos para sociedades sin asiento". En: Sociedades Movedizas. Pasos hacia una antropología de las calles. Barcelona: Editorial Anagrama, p.11 - 59 y p. 128 149.

Fortuny, P. (2010). "Espacios y sociabilidad entre migrantes mexicanos indocumentados. La iglesia como lugar de encuentro". En: Ciudad, espacio público y sociabilidad. Guadalajara: Universidad de Guadalajara, p. 21-55.

Ginzburg, C. (2008). "Prefacio" y "Cultura dominante y cultura subalterna” En: El queso y los gusanos. El cosmos según un molinero del siglo XVI. España: Ediciones Península, p. 9-33 у p.214-216.

Goffman, E. (1953). "El orden social y la interacción” En: Los momentos y sus hombres. España: Paidos, p. 91-98.

Joseph, Isaac (2002). “El extranjero traductor", “Precariedad” y “Rutinas”. En: El transeúnte y el espacio urbano. Barcelona: Editorial Gedisa, p. 11-34, 65-80 y 93 101.

Ruiz, M. C. (2009). "El concepto de actor en la metasistematización: claves metodológicas para la interpretación”. En: El conocimiento social en convivencia desde los escenarios de la Educación Popular. Cali: Programa Editorial Universidad del Valle, p. 81-90.

Sagástegui, D. (2010). “Utopía urbana y espacio público. Guadalajara, ciudad educadora”. En: Ciudad, espacio público y sociabilidad. Guadalajara: Universidad de Guadalajara, p. 245-287.

Recibido: Febrero 2016/ Aprobado: Abril 2016 